\title{
Comparative Study of Explosive Strength among Boxers and Taekwondo Players of Osmania University Hyderabad India
}

\author{
Janagama Prabhakar Rao \\ President, Indian Federation of Computer Science in Sports \\ Osmania University \\ Hyderabad, India \\ jprabhakarrao_ou@yahoo.com
}

\author{
Yerraguntla Emmanuel Shashi Kumar \\ Chairman, Indian Federation of Computer Science in Sports \\ Osmania University \\ Hyderabad, India \\ jprabhakarrao_ou@yahoo.com
}

\begin{abstract}
Boxing is a combat sport where two boxers fight (box) each other with both their hand and knuckles (fist). Boxers wear a glove weighing 10 ounce in a ring square of 24 feet and height 3-4 feet. The ring square is made of 4 ropes that are 20 feet long each. A punch in boxing consists of synchronization between arm, leg, and trunk actions. Taekwondo is characterized by its emphasis on head-height kicks, jumping and spinning kicks, and fast kicking techniques. The Significance of this study is to determine the explosive strength among boxers and taekwondo players of Osmania University, and the main objective of this study is to determine the explosive strength in the legs of boxers and taekwondo players. Thirty (30) male boxer and thirty (30) male taekwondo players of Osmania University were used as samples in this study. To assess their explosive strength, Standing Broad Jump Test was conducted among boxers and taekwondo players. From the result of this study, it was found that takwondo players have more explosive strength in their legs compare to boxers. A Taekwondo punch, much like boxing, involves triple extension whereby the ankle, knee, and hip extend to generate force from the ground. The more effective and powerful the coordination between arms, legs, and trunk movements are, the greater the impact of a punch. .The leg muscles and explosive strength in the legs play a vital role in the development of power in this sequence. Increasing the development of leg force, and coordinating it with trunk and arm action is probably the most effective and efficient way to increase punching power. Explosive strength plays a major role in producing punch power among taekwondo players. This study is helpful to coaches to train taekwondo players on how to increase explosive power ability in their legs, and to increase their punching speed.
\end{abstract}

Keywords-explosive strength, standing broad jump, taekwondo players, boxers

\section{INTRODUCTION}

Boxing is a combat sport where two boxers fight (box) each other with both their hand and knuckles (fist). Boxers wear a glove weighing 10 ounce in a ring square of 24 feet and height 3-4 feet. The ring square is made of 4 ropes that are 20 feet long each. A punch in boxing consists of synchronization between arm, leg, and trunk actions. Taekwondo is characterized by its emphasis on head-height kicks, jumping and spinning kicks, and fast kicking techniques.
The Significance of this study is to determine the explosive strength among boxers and taekwondo players of Osmania University, and the main objective of this study is to determine the explosive strength ability in the legs of boxers and taekwondo players.

Most sports require explosive power, and this is because when athletes move their bodies or any object with weight, they use power. The more the weight they move, the more the power that is needed. For taekwondo players, it is vital to be able to move their bodies as lightening speed, as in stepping movement; but also able to move their limbs, legs particularly in order to kick fast and their hands for blocking and punching. Taekwondo strength training exercises concentrate more on the lower body, upper body and arms, and core/abdominal area. According to Matthews and Comfort (2008), it involves the use of contrasting loads to elicit an acute enhancement in power output.

Boxing and Taekwondo are the sports that require explosive and powerful movements for an athlete to be able to succeed. Plyometrics mimics the physical demands of a fight and it helps to train the body to move more quickly and explosively.

Prof. Rajesh Kumar et al., (2013) in his study about the speed, agility, and power among boxers and taekwondo players of Osmania University, he concluded that boxers have good speed and power, while taekwondo players have good agility.

\section{MethodOLOGY}

The samples used in this study consist of thirty (30) male boxers and thirty (30) male taekwondo players of Osmania University. To assess their explosive strength, Standing Broad Jump Test was conducted among boxers and taekwondo players.

\section{A. Standing Broad Jump}

The Standing long jump also called the Broad Jump is a common and easy to administer test of explosive leg power.

\section{B. Purpose}

The purpose of Standing Broad Jump Test is to measure the explosive power of the legs. 
Equipment required: Measurement tape to measure the distance jumped, non-slip floor for takeoff, and soft landing area preferred. Commercial Long Jump Landing Mats are also available and the takeoff lines are marked clearly.

\section{Procedure}

The athlete stands behind a line marked on the ground with feet slightly apart. A two foot take-off and landing is used, with swinging of the arms and bending of the knees to enable forward drive. The suspect jumps as far as possible landing on both feet, without falling backwards.

Scoring: The measurements were taken from take-off line to the nearest point of contact on landing (back of the heels). The longest distance jumped out of the best three attempts made was recorded.

\section{RESULTS AND DISCUSSION}

TABLE I. SHOWING THE MEAN VALUES AND INDEPENDENT SAMPLES TEST OF STANDING BROAD JUMP BETWEEN TAEKWONDO PLAYERS AND BOXERS OF OSMANIA UNIVERSITY

\begin{tabular}{|c|c|c|c|c|}
\hline Variables & Group & Mean \pm SD & t & P - Value \\
\hline $\begin{array}{c}\text { Standing } \\
\text { Broad } \\
\text { Jump }\end{array}$ & Taekwondo Players & $2.30 \pm 0.157$ & 3.5 & 0.001 \\
\cline { 2 - 3 } & Boxers & $2.26 \pm 0.159$ & 5 & \\
\hline
\end{tabular}

*Significant at 0.05 level

In Table 1 above, the mean values of taekwondo players in Standing Broad Jump is 2.30, while that of boxers is 2.26. The Standard Deviation (SD) of taekwondo players is 0.157 while that of boxers is 0.159 . Also, ' $t$ ' value is 3.55 and $\mathrm{P}$ value is 0.001 .

It was discovered that taekwondo players have good explosive strength in their legs compare to boxers. A Taekwondo punch much like boxing, involves triple extension whereby the ankle, knee, and hip extend to generate force from the ground. The more effective the coordination between arms, legs, and trunk movements, the greater the force of impact of a punch. The leg muscles and explosive strength in leg plays a vital role in the development of power in this sequence. Increasing the development of leg force, and coordinating it with trunk and arm action is probably the most effective way to increase punching power. Explosive strength plays a major role in producing punch power among taekwondo players.

\section{CONCLUSIONS}

In this study, it was discovered that taekwondo players have good explosive strength in legs compare to boxers. Therefore, it is concluded that core training is essential for the development of speed and power in boxing and taekwondo.

\section{RECOMMENDATIONS}

It is recommended that similar studies should be conducted among females, and in other sports and games. This study is useful to coaches to prepare a conditioning program that will improve the skills of boxing and taekwondo players. This study is also useful to coaches to coach taekwondo and boxing players on how to increase the explosive power ability in their legs and also increase their punching speed.

\section{ACKNOWLEDGMENT}

I am very grateful to Mr. K. R. Steven, boxing coach and Mr. J. Babulal, taekwondo coach for their help in the success of this study.

\section{REFERENCES}

[1] A. Bejan, S. Lorente, J. Royce, D. Faurie, T. Parran, M. Black, \& B Ash, "The constructal evolution of sports with throwing motion: Baseball, golf, hockey and boxing," International Journal of Design \& Nature and Ecodynamics, 8(1), 1-16. 2013.

[2] M. Matthews, \& P. Comfort, "Applying complex training principles to boxing: A practical approach," Strength \& Conditioning Journal, 30(5), 12, 2008 .

[3] R. Kumar, P. Supriya, P. A. Reddy, G. R. Devi, "A Comparative Study of Speed,Agility and Power among Boxers and Taekwondo Players of Osmania University," International Journal of Health, Physical Education and Computer Science in Sports, 2013, Vol.12 page.71

[4] https://taekwondoanimals.com/taekwondo-strength-training

[5] http://warriorpunch.com/boxing-training-workout-speed 